\title{
Forecasting FTSE Index Using Global Stock Markets
}

\author{
Jose G. Vega \\ College of Business Administration \\ University of Texas San Antonio \\ One UTSA Circle, San Antonio, TX 78249, USA \\ Jan M. Smolarski (Corresponding author) \\ College of Business Administration \\ University of Texas Pan American \\ 1201 W. University Drive, Edinburg, TX 78539, USA \\ E-mail: jmsmolarski@utpa.edu
}

Received: December 28, 2011

doi:10.5539/ijef.v4n4p3
Accepted: January 16, $2012 \quad$ Published: April 1, 2012

URL: http://dx.doi.org/10.5539/ijef.v4n4p3

\begin{abstract}
Using data from July 1997 to July 2007, we examine if the FTSE index is affected by the past behavior of the DOW, DAX, NIKKEI, Hang Seng and Shanghai indices. We compare three different methods of estimating regression parameters. The results show that the FTSE lagged variable and the NIKKEI and DOW past performance are good indicators of the future performance of the FTSE. The models produce different predictive values but the effect of the variables is the same when examining the direction of the coefficients. Both the Newey-West OLS and GARCH models are better predictive models than the OLS with a standard error. The predictive power of the model increases as a result of allowing time varying variances.
\end{abstract}

Keywords: Spill-over, Newey-West, Co-movements, Stock Index

GEL Classification Codes: C52, G15, M49

\section{Introduction}

As world economies become more integrated, co-movements among international equity markets have become more evident (Chong, Wong and Yan; 2008). There are a number of reasons to expect integration. Examples often cited include the availability of information, round-the-clock trading and financial innovations. Tsouma (2007) show that the number of stock exchanges has increased and that established exchanges have expanded their activities. A substantial number of articles have addressed the issue of co-movements and spill-over effects but the results are not always consistent, especially over long-time periods and across different stock markets. Relying on the chronological order of trading and a careful definition of daytime and overnight returns, most studies confirm the existence of some form of co-movement, spill-over effect and, therefore, interdependence among leading global stock markets. The magnitude of the effects and the time period over which these effects exist are inconsistent (Baur and Jung, 2006). While research continues on the many aspects of co-movements and spill-over effects, there are three conclusions that researchers agree upon. First, existing research shows that some, but not all, stock markets are interdependent. Second, long-term relationships are for the most part non-existent (e.g. Fernandez-Serrano and Sosvilla-Rivero, 2001). Third, small changes in indices in the US, UK, Germany and Japan do not affect other indices (Hirayama and Tsutsui, 1998). There are also a number of trends in existing research. We observe that stock-market integration is progressive (Morana and Beltratti, 2008) and that a consistent theme is that the DOW is a good predictor of global indices but other global indices are not good predictors of the DOW (Note 1,2). The exception to the general rule is the NIKKEI index, which we will discuss shortly.

In analyzing studies prior to 2000, a common methodological theme is the analysis of announcement effects in relationship to co-movements and spillover effects. A number of studies have analyzed how opening and closing prices are related (Note 3). Past studies have also examined the linkage between international indices, mostly focusing on the DOW in relationship to other global indices. A common finding in these studies is that US stock markets have a significant impact on Japanese equities. In one of the earlier studies; Becker, Finnerty and Gupta 
(1990) found that S\&P 500 one-day returns explained $7 \%$ to $25 \%$ of the fluctuations of the NIKKEI next day returns demonstrating that the US market greatly influences Japan. They were also able to show that up to $18 \%$ of the fluctuations in the overnight NIKKEI returns were attributable to the past performance of the US market. Evidence also suggests that the NIKKEI affects returns in some markets but not others. Using an impulse response functions, Chowdhury (1994) found that the response of the Hong Kong and Singapore stock markets to a shock in either the Japanese or US stock markets were absorbed within two days. Chong, Wong and Yan (2008) found that studies using recent data reveal additional evidence of transmission from the US to the Japanese markets. Using Japan as the core country of their analysis, they concluded that the Japanese stock market has a lead-lag relationship to other stock markets. In examining the synchronization of stock price movements, they found various lead-lag effects from the open-to-close return of stocks in Toronto, Paris, Frankfurt, London, Milan and New York Stock Exchange compared to the Japanese equity market. Chong et al (2008) also found that the NIKKEI index is well predicted by the movement of the FTSE Index. Regardless of the trigger level, the results revealed that the next day market performance in Japan can be predicted using signals from other markets. Focusing on markets other than Japan, Arshanapalli and Doukas (1993) found that the French, German and UK markets were not significantly related to the US markets prior to the stock market crash of 1987. Post-1987 results showed that these markets co-integrated significantly with the US stock market. Focusing on short-term information transmission, Baur and Jung (2006) analyzed correlation and spillover effects between the DOW and the DAX. They found that foreign daytime returns can influence overnight domestic returns. The effect was more pronounced in Germany. Johansson and Ljungvall (2009) showed spillover effects among the Chinese, Hong Kong and Taiwanese stock markets although there were no clear long-term interdependencies. Interestingly, the Taiwanese and Hong Kong markets influence the mainland Chinese markets but the Chinese market does not influence the other two markets. We conclude that existing research shows that markets are integrated but that level of integration requires further study.

There are at least four important reasons why the examination of market integration is important. First, international portfolio diversification depend on less than perfect co-movements and spill-over effects. Second, progressive integration implies increased market volatility. Third, a shock in one market is likely to have a pronounced effect in other markets suggesting that different hedging behaviors are needed. Fourth, market shocks are likely to have a larger global effect than previously. In this study, we examine the effect of the lagged indices of DOW, DAX, NIKKEI, Shanghai, HangSeng on the lagged FTSE index. To deal with some methodological issues encountered in many studies, we also examine three different methods of estimating regression parameters: (1) the OLS model with the standard error; (2) the OLS model with the Newey-West standard error, and (3) the GARCH model. Below, we discuss the models followed by a discussion about their application.

Many studies use OLS although it is well known that it yields inconsistent estimates if used in combination with lagged variables and correlated errors (Stocker, 2006). In addition, a standard OLS model has several assumptions that need to be met in order for the model to be valid. The residuals, $\mu_{t}$, should be normally distributed with zero mean and constant variance (no heteroscedasticity). Financial data is known to be leptokurtic resulting in fat tails (Boyer et al, 2003). In addition; the error terms, $\mu_{\mathrm{t}}$, should be uncorrelated. If the error term $\mu_{\mathrm{t}}$ is auto-correlated, then OLS is consistent, but in general the OLS standard errors for cross-sectional data are not (Stock and Watson, 2007). Finally, the independent variables should not be highly correlated, thus avoiding multicollinearity. Using Newey-West standard errors, we correct for issues of unspecified heteroscedasticity and autocorrelation (HAC). A Newey-West estimator reduces the frequency of over-rejection ( $\mathrm{Su}, 2008)$ and produces robust results (Park, 2005).

The ARCH process introduced by Engle (1982) allows the conditional variance to change over time as a function of past errors leaving the unconditional variance constant (Bollerslev, 1986). In response to Engle, Bollerslev (1986) introduced the GARCH method, which is an extension of the ARCH method by letting its own $\sigma_{t}^{2}$ depend on its lagged value. The GARCH model provides a better fit than the ARCH model since it uses a declining lag structure similar to Engle and Kraft (1983).

Our study examines if global indices have an effect on the percent change (return) of the FTSE based on analyzing past performance of five global indices. We also examine different methods of regression to predict the FTSE index. A commonly used method is the OLS regression model. As we discussed previously, several assumptions of the OLS model are regularly violated and the models also ignores much of the relevant information (Morana and Beltratti, 2008). If the assumptions of the OLS model are ignored, a Type 1 error is significantly more likely to occur. In reality, this means that the standard error and hypothesis testing may be inaccurate and therefore cause a Type 1 error. To deal with this issue, we also include a second OLS model with a Newey-West standard error. This method adjusts for the inaccuracies of the OLS standard error and hypothesis testing that is commonly encountered when using financial time series data. The GARCH model is the last of the three regression models evaluated in this study. It allows the variance to change through the regression model. Using the GARCH model, we relax several 
assumptions of regression models dealing with normality, linearity, and homoskedasticity. Therefore, our study also enhances the literature by incorporating different regression methods in testing and subsequent analysis.

Examining the results of the OLS and the Newey-West error term models, we note that they show similar results, i.e. that the past performances of the lagged FTSE, the NIKKEI and the DOW appear to be good indicators of future performance of the FTSE. The GARCH model also produces similar results. Using ANOVA, we show that the standard errors of the models are different from each other. The results suggest that there is a difference in the predicted values using each technique leading us to state the following. First, we predict that global indices will have an effect on the future performance of the FTSE. Second, we predict that the different regression models will show different results. We now turn our attention to discussing the details of our methodology and we provide an in-depth discussion of the results.

\section{Methodology}

This study uses 2608 daily observations from DATASTREAM for each international index during the period of July 1997 to July 2007. The variables are tested for normality (Skewness, Kurtosis), linearity (Graphs), and correlation (Correlation Matrix) between the dependent and independent variables before regression parameters are estimated. The dependent variable is the UK FTSE index and the independent variables are the US DOW index, the Japanese NIKKEI index, the Hong Kong HANG SENG index, the SHANGHAI index (China) and the German DAX index. We use the percent change (return) for each of the indices to standardize the data across all indices. We transform the daily index by the natural logarithm for each day, then subtracting the past day return from the current day return to obtain the percent change (return) of daily index values. Using the natural logarithm of the indices helps ensure that the data meets the assumption of linearity, an important issue when using different multiple regression models.

As we discussed previously, it is well known that financial time series data do not follow many of the assumptions in linear multiple regression (Gungor and Luger, 2009). We use three different regression methods in our study: (1) the OLS model, (2) the OLS model with a Newey-West error term, and (3) the Generalized Autoregressive Conditional Heteroskedasticity $(\mathrm{GARCH})$ model. The regression model has a lagged variable of the dependent variable making it an autoregressive model. We now discuss the models. The regression model states:

$$
\text { FTSE }_{t}=\beta_{0}+\beta_{1} \text { FTSE }_{t-1}+\beta_{2} \text { DAX }_{t-1}+\beta_{3} \text { NIKKEI }_{t-1}+\beta_{4} \text { DOW }_{t-1}+\beta_{5} \text { HangSeng }_{t-1}+\beta_{6} \text { Shanghai }_{t-1}+\mu_{t}
$$

- FTSE $_{t}$ is the present day percent change for the FTSE index,

- $\beta_{0}$ is the intercept,

- $\quad \beta_{1}$ FTSE $_{t-1}$ is the lagged variable of the FTSE percent change of the FTSE index,

- $\beta_{2} \mathrm{DAX}_{\mathrm{t}-1}$ is the lagged variable of the DAX index,

- $\quad \beta_{3}$ NIKKEI $_{t-1}$ is the lagged variable of the NIKKEI index,

- $\quad \beta_{4} \mathrm{DOW}_{\mathrm{t}-1}$ is the lagged variable of the DOW index,

- $\beta_{5}$ HangSeng $_{t-1}$ is the lagged variable of the Hang Seng index,

- $\quad \beta_{6}$ Shanghai $_{\mathrm{t}-1}$ is the lagged variable of the Shanghai index, and

- $\mu_{\mathrm{t}}$ is the error term of the regression model.

The difference between the OLS model and the Newey-West model is the treatment of the standard error. The standard error for both of the models is calculated as follows:

$$
S E\left(\hat{B}_{1}\right)=\sqrt{\hat{\sigma}_{B_{1}}^{2}}
$$

where the variance is calculated as:

$$
\hat{\sigma}_{B_{1}}^{2}=\frac{1}{n} * \frac{\frac{1}{n-2} \sum_{i=1}^{n}\left(X_{i}-\bar{X}\right)^{2} \hat{\mu}_{i}}{\left[\frac{1}{n} \sum_{i=1}^{n}\left(X_{i}-\bar{X}\right)^{2}\right]^{2}}
$$

The difference between the two models is the inflation of the variance with the heteroskedasticity and autocorrelation consistent estimator of the variance of $\hat{B}_{1}$ is:

$$
\tilde{\sigma}_{B_{1}}^{2}=\hat{\sigma}_{B_{1}}^{2} \hat{f_{T}}
$$


where $\hat{\sigma}_{B_{1}}^{2}$ is the estimator of the variance of $\hat{B}$ in the absence of serial correlation. The $\hat{f}_{T}$ is an estimator of the factor $\mathrm{f}_{\mathrm{T} .}\left(\right.$ Stock and Watson, 2007). Let $\hat{f}_{T}$ is defined as Newey-West variance estimator:

$$
\hat{f}_{T}=1-2 \sum_{j=1}^{m-1}\left(\frac{m-j}{m}\right) \tilde{p}_{j}
$$

where $\tilde{p}_{j}=\sum_{t=j+1}^{T} \hat{V_{t}} \hat{V_{t-j}} / \sum_{t=1}^{T} \hat{V_{t}^{2}}$ where $\hat{V_{t}}=\left(X_{t}-\bar{X}\right) \hat{\mu_{t}}$ (as in the definition of $\hat{\sigma}_{\beta}^{2}$ ). The parameter $m$ is called the truncation parameter of the HAC estimator (Stock and Watson 2007).

The GARCH model mean equation is stated as:

$$
\text { FTSE }_{t}=\beta_{0}+\beta_{1} \text { FTSE }_{t-1}+\beta_{2} D A X_{t-1}+\beta_{3} \text { NIKKEI }_{t-1}+\beta_{4} D O W_{t-1}+\beta_{5} \text { HangSeng }_{t-1}+\beta_{6} \text { Shanghai }_{t-1}+\mu_{t}
$$

- $\mathrm{FTSE}_{t}$ is the present day percent change of the FTSE index,

- $\beta_{0}$ is the intercept,

- $\quad \beta_{1}$ FTSE $_{\mathrm{t}-1}$ is the lagged variable of the FTSE percent change of the FTSE index,

- $\beta_{2} \mathrm{DAX}_{\mathrm{t}-1}$ is the lagged variable of the DAX index,

- $\quad \beta_{3}$ NIKKEI $_{t-1}$ is the lagged variable of the NIKKEI index,

- $\beta_{4} \mathrm{DOW}_{\mathrm{t}-1}$ is the lagged variable of the DOW index,

- $\beta_{5}$ Hang Seng $_{\mathrm{t}-1}$ is the lagged variable of the HangSeng index,

- $\quad \beta_{6}$ Shanghai $_{t-1}$ is the lagged variable of the Shanghai index, and

- $\mu_{t}$ is the error term for the regression model.

The first method is Ordinary Least Squares (OLS), which if unbiased, is consistent, has a variance that is inversely proportional to $n$, and has a normal sampling distribution when the sample size is large (Stock and Watson, 2007). Serial correlation may present itself when using a lagged variable of the dependent variable. This issue causes autocorrelation or heteroskedasticity with the error term. If this is the case, the coefficient estimators are consistent but OLS standard errors are not, resulting in misleading testing and confidence intervals (Stock and Watson, 2007). This leads us to the OLS with Newey-West error term models. The Newey-West error term adjusts for heteroskedasticity and autocorrelation in the regression model. The Newey-West error term OLS model replaces the standard error with an HAC error term, which makes the method more appropriate for financial time series data.

The GARCH model is the third model that we examine and it allows for a time-changing variance. It accomplishes this by letting the error, $\mu_{t}$, being normally distributed with mean zero and variance $\sigma_{t}^{2}$ depend on past squared values of $\mu_{\mathrm{t}}$ and letting the $\sigma_{\mathrm{t}}^{2}$ depend on its lagged value (Stock and Watson, 2007).

$$
\sigma_{t}^{2}=\alpha_{0}+\alpha_{p} \mu_{t-p}^{2}+\phi_{1} \sigma_{t-1}^{2}+\ldots+\phi_{q} \sigma_{t-q}^{2}
$$

Based on the previous discussion, we examine the error term of each model and tests if the means are similar. To test the model errors to evaluate if the means of the error are similar, we use ANOVA (Note 4). We test the difference between the OLS and the Newey-West model by comparing the standard error of the predicted values. The GARCH model will have different predictive values since it produces different coefficients. We are, therefore, able to compare the predicted values of the GARCH model and the predicted values of the OLS and OLS Newey-West standard error models. The results are then analyzed against each other using a one-way ANOVA test.

\section{Results}

In this section we discuss the results beginning with descriptive statistics, which are shown in Table 1 (Note 5). Each variable is examined in terms of the aspect of normally distributed skewness and kurtosis values. If a variable has a long right tail, the skewness value will be positive, and if the variable has a long left tail, the skewness value will be negative. The normal kurtosis value is 3 suggesting that if a variable have a number greater then 3 , the distribution will have a substantial peak, and if the value is less than 3 , the distribution will be flatter.

\section{Insert Table 1 Here}

Evaluating the FTSE return variable shows a left tail distribution with a value of -.101, as well as a substantial peak (5.678). The FTSE return lag variable has a skewness value of -.102 and a kurtosis value of 5.675 indicating that it has a left tail and a substantial peak. The DAX Return lag variable has a skewness of -.106 showing a left tail 
distribution. The kurtosis value of 5.825 shows a distributional peak. The variable NIKKEI Return lag has values of -0.030 showing less of a left tail and a kurtosis value of 5.228. The DOW return lag has a skewness value of -.117 showing a left tail distribution and a kurtosis value of 7.398 indicating a substantial peak in the distribution. The HANG SENG return lag variable shows a peak in the distribution with a kurtosis value of 16.500 and a right tail skewness value of .501. The SHANGHAI return lag has a right tail distribution with a skewness value of .191 and a peak in the distribution with a kurtosis value of 8.833. Evaluating the variable as a whole, it shows a substantial peak in the distribution with no kurtosis value less than 5.1. We conclude that variables are skewed and that the kurtosis values are more extreme.

Insert Table 2 Here

To evaluate the linearity of the independent variables and to perform a comparison with the dependent variable, the variables were graphed against each other (see table 2). The FTSE, DAX, NIKKEI, DOW, and SHANGHAI return lag variables all show some linearity toward the dependent variable. The HANG SENG return lag shows no linearity towards the dependent variable. The evaluation of the substantial linearity of the variables shows that only the DOW return lag has a substantial linear relationship with the FTSE Return. This result is expected in time-series data. We now examine the results of the correlation matrix.

Insert Table 3 Here

An examination of table 3 shows the highest correlated variable of the FTSE return is the DOW return lag variable with a correlation of 0.270 . There is concern that the DOW return lag variable is also highly correlated to the FTSE return lag and the DAX return lag variables, which may indicate that multicollinearity is present. HANG SENG is also highly correlated to the FTSE return lag, DAX return lag, and the NIKKEI return lag variables. Similarly, this may cause multicollinearity in the regression model. Finally, the DAX return lag is highly correlated to the FTSE return lag variable. Highly correlated independent variables suggest over-estimation of the regression model.

Insert Table 4 Here

Table 4 shows the regression results. The results from the OLS model show an F-statistic of 47.02 indicating that the overall model as being statistically significant at a .000 level. The Adjusted $\mathrm{R}^{2}$ value is low at .0958 . Examining the regression coefficients of the OLS model, the FTSE return lag has a coefficient of -0.0028 showing that with every unit increase in the past FTSE return, the future FTSE return will decrease by 0.012 . This is statistically significant (t-value of -3.59). The DAX return lag has a statistically insignificant coefficient of -0.035 . The NIKKEI return lag has a coefficient of -0.055 , showing that with every unit increase the future FSTE return will decrease by 0.055 . This is statistically significant ( $\mathrm{t}$-value $=-3.29$ ). The DOW return lag has a coefficient of 0.362 showing that with every unit increase, the future FTSE return will increase by 0.362 . The result is highly significant $(\mathrm{t}=16)$. The HANG SENG return lag and the SHANGHAI return lag coefficients are statistically insignificant (Note 6).

The results from the OLS model with the Newey-West standard error shows that the overall model is statistically significant at the .000 level $(\mathrm{F}$-statistic $=28.58)$. Examining the regression coefficients of the Newey-West model, the FTSE return lag has a coefficient of -0.102 , showing that with every unit increase in the past the FTSE return and the future FTSE Return will decrease by 0.102 . This is statistically significant $(t=-2.55)$. The DAX return lag is statistically insignificant. The NIKKEI return lag has a coefficient of -0.055 suggesting that with every unit increase the future FSTE return will decrease by 0.055 . The results are statistically significant $(\mathrm{t}=-2.61)$. The DOW return lag has a coefficient of 0.362 . The result is highly statistically significant $(t=12.2)$. The HANG SENG return lag and the SHANGHAI return lag coefficients are statistically insignificant.

The evaluation of the GARCH model shows a highly significant $\chi^{2}$ value, which is statistically significant at the .000 level. Examining the regression coefficients, FTSE return lag has a coefficient of -.072, showing that with every unit increase in the past FTSE return the future FTSE return will decrease by .072 . The result is statistically significant $(\mathrm{t}=-2.71)$. The DAX return lag has a coefficient of -0.056 , which is statistically significant $(\mathrm{t}=-3.05)$. The NIKKEI return lag has a coefficient of -0.036 . This is statistically significant $(\mathrm{t}=-2.58)$. The coefficient the DOW return lag is 0.323 , showing that with every unit increase, the future FTSE return will increase by 0.323 . This is highly significant $(\mathrm{t}=15.5)$. The coefficients of the HANG SENG return lag and the SHANGHAI return lag are insignificant.

The results from all three of the regression models have supported our first prediction showing the global indices have an effect on the future return of the FTSE index. Not all indices affect on the future return of the FTSE index, however. Discussing the results from the OLS and Newey-West tests; the FTSE return lag, DAX return lag, and DOW return lag have a statistically significant effect on the future return of the FTSE. The HANG SENG return lag, NIKKEI return lag, and the SHANGHAI return lag are not statistically significant in predicting FTSE future returns. 
The GARCH model show similar results supporting our first prediction that the performance of some past global indices has a statistically significant effect on future FTSE index returns.

\section{Insert Table 5 Here}

We use ANOVA to test for statistically significant differences between the standard error of the OLS model and the Newey-West model. Table 5, Panel A shows a statistical difference between the mean of the two models. The F-static of 220.62 is statistically significant at a .000 level. The results support the prediction that the different regression model will produce different results. The difference between the OLS and Newey-West is the treatment of the standard error. In the Newey-West model, the standard error is inflated, which reduces the t-statistic resulting in a lower likelihood of a Type 1 error. We also used ANOVA to test if there is a significant difference between the predicted values of the GARCH compared to the predicted values of the OLS models. Evaluating the results in Table 5, Panel B, there is a statistically significant difference between the predicted values of the GARCH and the OLS model with an F-static of 9.452 , which is statistically significant at a .000 level. This result also supports the second prediction showing that there is a difference between the OLS and GARCH models.

\section{Discussion}

The results support both predictions that we test in our study. When analyzing the effect of global indices, three results show that past performance of the two indices and in the case of the GARCH model, three indices have an effect on FTSE returns. The lag variable of the FTSE is statistically significant but the negative coefficient suggests that past behavior of the FTSE has a negative effect on the future return of the FTSE. This is an interesting finding since it suggests that a positive FTSE index performance does not carry forward. On the other hand, the results also suggest that a negative return will carry a positive reaction towards the future price of the FTSE index. The DOW return lag has the most substantial effect towards the future return of the FTSE with the greatest t-value and highest coefficient. This is the only variable that has a positive effect on the future price of the FTSE. It shows that a positive return on the DOW will carry a positive return toward the future return of the FTSE. All three regression models support this finding. The other indices have a negative effect on the future price of the FTSE showing that a positive return will have a negative impact on the future returns of the FTSE index. In evaluating the regression models, is important to examine the results of the coefficients for the variables in each model. The three models all suggest the same coefficient direction for all variables, and that the GARCH model is different in the sense that the NIKKEI return lag is statistically significant. It is not statistically significant in the two other regression models. This is an important finding, because although the models produce different predictive values, the effect of the variables is the same when examining the coefficient direction. This study also shows that OLS under-estimates the standard error, thus increasing the likelihood of a Type 1 error while the Newey-West model reduces the possibility of a Type 1 error. Both OLS and the Newey-West model have similar predictive power because the coefficients of the betas are the same. The GARCH model, on the hand, not only helps in reducing the likelihood of a Type 1 error, but the predictive power of the model increases as a result of allowing time varying variances.

\section{Conclusion}

We offer two types of conclusions in this paper. First, this study supports the hypothesis that some international indices have predictive powers toward the future performance of the FTSE index. All three regression models support the main result. Our study also shows that the three regression models will provide different results concerning predictive variables but that all variables maintain the same direction of the coefficients. The results suggest that although the regression models are different, they do support each other's findings. Future studies should examine the different effects that other international indices have on the return of the FTSE. With constantly changing global capital markets, information is being processed and past along faster than ever. This could cause even smaller indices to have an effect on larger global indices, not only the other way around. This should be examined in future studies. Our study only covers a time frame of ten years, from July 1997 to July 2007. The results may not hold when evaluating different time frames. Second, the results show that the predictive power of the OLS and Newey-West models are similar but the Newey-West model is more efficient. Based on the results of our study, we conclude that OLS and Newey-West models should only to be used to explain results when dealing with time series data. With respect to predicting an outcome, a GARCH model should be used.

\section{References}

Arshanapalli, B., \& Doukas, J. (1993). International stock market linkages: evidence from the pre- and post-october 1987 period. Journal of Banking \& Finance, 17, 193 - 208. http://dx.doi.org/10.1016/0378-4266(93)90088-U

Asimakopoulos, J., Goddard, J., \& Siriopoulos, C. (2000). Interdependence Between the US and Major European Equity Markets: Evidence from Spectral Analysis. Applied Financial Economics, 10: 41 - 47. 
http://dx.doi.org/10.1080/096031000331914

Baur, D., \& Jung, R. (2006). Return and volatility linkages between the US and German stock markets. Journal of International Money and Finance, 25, 598 - 613. http://dx.doi.org/10.1016/j.jimonfin.2005.11.010

Becker, K., Finnerty, J., \& Friedman, J. (1995). Economic news and equity market linkages between the US and UK. Journal of Banking \& Finance, 19, 1191 - 1210. http://dx.doi.org/10.1016/0378-4266(94)00079-I

Becker, K., Finnerty, J., \& Gupta, M. (1990). The intertemporal relation between the U.S. and Japanese stock markets. The Journal of Finance, 45, 1297 - 1306. http://dx.doi.org/10.2307/2328726

Bollerslev, T. (1986). Generalized autoregressive conditional heteroskedasticity. Journal of Econometrics, 31, 307 327. http://dx.doi.org/10.1016/0304-4076(86)90063-1

Boyer, B., McDonald, J., \& Newey, W. (2003). A comparison of partially adaptive reweighted least square estimation, Econometric Reviews, 22, 115 - 134. http://dx.doi.org/10.1081/ETC-120020459

Chong, T., Wong, Y., \& Yan, I. (2008). International linkages of the Japanese stock market. Japan and the World Economy, 20, 601 - 621. http://dx.doi.org/10.1016/j.japwor.2007.06.004

Chowdhury, A. R. (1994). Stock market interdependencies: evidence from the Asian NIEs. Journal of Macroeconomics, 16, 629-651. http://dx.doi.org/10.1016/0164-0704(94)90004-3

Cook, D., Kieschnick, R., \& B. McCullough, B. (2008). Regression analysis of proportions in finance with self-selection. Journal of Empirical Finance, 15, 860 -867. http://dx.doi.org/10.1016/j.jempfin.2008.02.001

Engle, R., \& Kraft, D. (1983). Multi-period forecast error variances of inflation estimated from ARCH models. In: A. Zellner, Editor. Applied Time Series Analysis of Economic Data, Bureau of the Census, Washington, DC, 293 - 302.

Engle, R. F. (1982). Autoregressive conditional heteroskedasticity with estimates of the variance of United Kingdom inflation. Econometrica, 50, 987 - 1007. http://dx.doi.org/10.2307/1912773

Eun, C., \& Shim, S. (1989). International Transmission of Stock Market Movements. Journal of Financial and Quantitative Analysis, 24 (2): 241 - 256. http://dx.doi.org/10.2307/2330774

Fernandez, J., \& Sosvilla-Rivero, S. (2001). Modeling evolving long-run relationships: the linkages between stock markets in Asia. Japan and the World Economy, 13, 145 - 160. http://dx.doi.org/10.1016/S0922-1425(01)00054-8

Gungor, S., \& Luger, R. (2009). Exact Distribution Free Tests of Mean-variance Efficiency. Journal of Empirical Finance, 16: 816 - 829. http://dx.doi.org/10.1016/j.jempfin.2009.06.003

Hirayama, K., \&Tsutsui, Y. (1998). Threshold effects in international linkages in stock prices. Japan and the World Economy, 10, 441 - 453. http://dx.doi.org/10.1016/S0922-1425(98)00021-8

Johansson, A., \& Ljungvall, C. (2009). Spillover effects among greater china stock markets. World Development, 37, 839 - 851. http://dx.doi.org/10.1016/j.worlddev.2008.07.015

Lawford, S., \& Stamatogiannis, M. (2009). The finite-sample effects of VAR dimensions on OLS bias, OLS variance and minimum MSE estimators. Journal of Econometrics, $148,124-130$. http://dx.doi.org/10.1016/j.jeconom.2008.10.004

Morana, C., \& Beltratti, A. (2008). Aggregate hedge funds' flow and returns. Applied Financial Economics, 18, $1755-1764$.

Park, C. (2005). Stock return predictability and the dispersion in earnings forecasts. Journal of Business, 75, 2351 2375. http://dx.doi.org/10.1086/497047

Smith, J., \& McAleer, M. (1994). Newey-West covariance matrix estimates for model with generated regressors. Applied Economics, 26, 635 - 640. http://dx.doi.org/10.1080/00036849400000034

Stock, J., \& Watson, M. (2007). In Pearson A. W. (Ed.), Introduction to econometric (Pearson ed.), Boston MA 02116.

Stocker, T. (2006). On the asymptotic bias of OLS in dynamic regression models with autocorrelation returns. Statistical Papers, 48, 81 - 93. http://dx.doi.org/10.1007/s00362-006-0317-8

$\mathrm{Su}, \mathrm{J}$. (2008). A note on spurious regressions between stationary series. Applied Economics Letters, 15, 1225 - 1230. http://dx.doi.org/10.1080/13504850601018106

Tai-Leung Chong, T., Wong, Y., \& Yan, Y. (2008). International linkages of the Japanese stock market. Japan and the World Economy, 20, 601 - 621. http://dx.doi.org/10.1016/j.japwor.2007.06.004 
Theodossiou, P., \& Koutmos, G. (1994). Linkages between the US and Japanese stock markets: a bivariate GARCH-M analysis. Global Finance Journal, 5, 277 - 287. http://dx.doi.org/10.1016/1044-0283(94)90008-6

Tsouma, E. (2007). Stock return dynamics and stock market dependencies. Applied Financial Economics, 17, 805 825. http://dx.doi.org/10.1080/09603100600749212

Von Furstenberg, G., \& Jeon, B. (1989). International Stock Price Movements: Links and Messages. Brookings Papers on Economic Activity, 1, 125 - 167. http://dx.doi.org/10.2307/2534497

West, K. (1987). A standard monetary model and the variability of the deutschemark-dollar exchange rate. Journal of International Economics, 23, 57 - 76. http://dx.doi.org/10.1016/S0022-1996(87)80005-3

\section{Notes}

Note 1. Many studies use the US as the core country.

Note 2. Becker, Finnerty and Friedman (1995) argued, based on reactions of UK traders to US announcements, that the two markets are linked. While we refer to these articles in our paper, we argue that tests similar to Becker et al (1995) are not direct tests of integration, co-movements and spillover effects. Rather, they are tests of consistent trader behavior across markets implying market integration.

Note 3. Becker, Finnerty, and Gupta (1990) found that there is no linkage between the open and closed returns of the US markets.

Note 4. Note that the OLS and the Newey-West error term naturally will have the same predicted value because the coefficients do not change. It is only the standard error that changes.

Note 5. We use one-time lagged indices ( $t-1)$ of independent variables to forecast the FTSE $(t)$. This approach does not take into account national holidays and time-zone bias, if any.

Note 6. We apply an arch test for heteroskedasticity and the Durbin-Watson alternative test for autocorrelation. The results of the arch test show a chi-square value of 134.98 , rejecting $\mathrm{H}_{0}$ that there is no arch effect. The results for the Durbin-Watson test also show a chi-square value of 19.392 , rejection $\mathrm{H}_{0}$ that there is no serial autocorrelation. OLS assumes that the error variance is constant and that the error terms are independent. These results suggest that the OLS coefficients may be inefficient and biased, which is why we employ Newey-West and GARCH methods.

Table 1. Descriptive Statistics

\begin{tabular}{lllll}
\hline Variable & Mean & Std. Dev. & Skewness & Kurtosis \\
\hline FTSE Excess Return & 0.0000127 & 0.0112889 & -0.1011822 & 5.678615 \\
FTSE Excess Return Lag & 0.0000172 & 0.0112906 & -0.1020578 & 5.675576 \\
DAX Excess Return Lag & 0.0002433 & 0.0158327 & -0.1064937 & 5.825191 \\
NIKKEI Excess Return Lag & 0.0000346 & 0.0140197 & 0.0307086 & 5.228309 \\
DOW Excess Return Lag & 0.0001459 & 0.0108305 & -0.1176092 & 7.397954 \\
HangSeng Excess Return Lag & 0.000184 & 0.0165701 & 0.5017384 & 16.50039 \\
Shanghai Excess Return Lag & 0.0005568 & 0.0144491 & 0.1915438 & 8.833616 \\
\hline Total Observations: 2608 & & & & \\
\hline
\end{tabular}


Table 2. Graph of FTSE Independent Variables
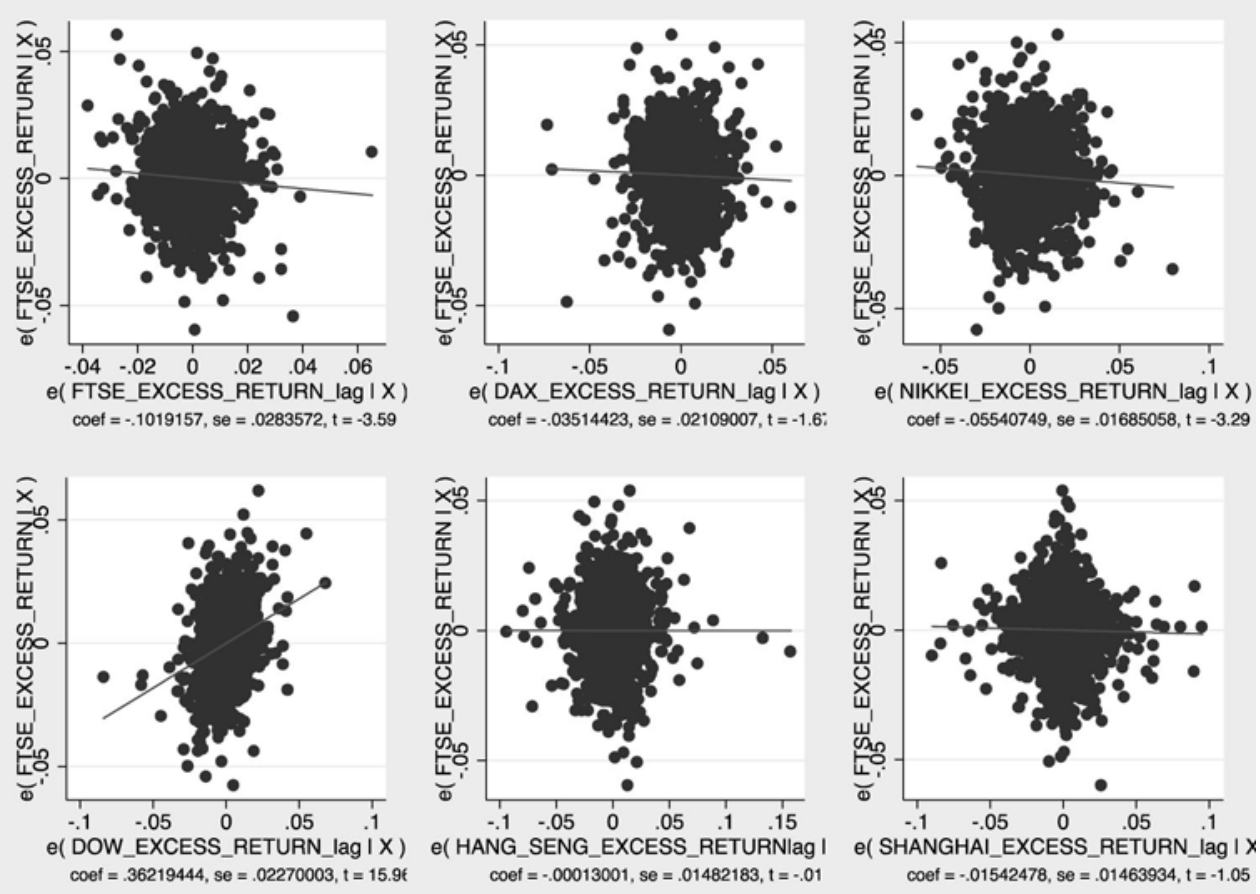

Table 2 shows the linear relationship between the dependent and the independent variable (independently). The FTSE, DAX, NIKKEI, DOW, and SHANGHAI return lag variables all show some linearity toward the dependent variable. The HANG SENG return lag shows no linearity towards the dependent variable. The evaluation of the linearity of the variables shows that only the DOW return lag has a substantial linear relationship with the FTSE Return

Table 3. Correlation Matrix

\begin{tabular}{lllllllll}
\hline & & 1 & 2 & 3 & 4 & 5 & 6 & 7 \\
\hline 1 & FTSE Excess Return & 1 & & & & & & \\
2 & FTSE Excess Return Lag & -0.0064 & 1 & & & & & \\
3 & DAX Excess Return Lag & 0.0371 & 0.7428 & 1 & & & & \\
4 & NIKKEI Excess Return Lag & -0.0638 & 0.2456 & 0.2228 & 1 & & & \\
5 & DOW Excess Return Lag & 0.2707 & 0.428 & 0.5107 & 0.1215 & 1 & & \\
6 & HangSeng Excess Return Lag & -0.0369 & 0.3377 & 0.3222 & 0.4433 & 0.1322 & 1 & \\
7 & Shanghai Excess Return Lag & -0.0286 & -0.0204 & -0.0044 & 0.0547 & -0.0211 & 0.0916 & 1 \\
\hline
\end{tabular}

Table 4. Regression Results

\begin{tabular}{|c|c|c|c|c|c|c|c|c|c|}
\hline \multirow[b]{2}{*}{ Variables } & \multicolumn{3}{|c|}{ OLS Model } & \multicolumn{3}{|c|}{ Newey-West Model } & \multicolumn{3}{|c|}{ GARCH Model } \\
\hline & Coefficients & Std. Error & t-statistic & Coefficients & Std. Error & t-statistic & Coefficients & Std. Error & t-statistic \\
\hline Intercept & -0.000019 & 0.000210 & -0.09 & -0.000019 & 0.000211 & -0.09 & 0.000259 & 0.000157 & 1.65 \\
\hline FTSE Excess Return Lag & -0.101916 & 0.028357 & -3.59 & -0.101916 & 0.040041 & -2.55 & -0.072516 & 0.026720 & -2.71 \\
\hline DAX Excess Return Lag & -0.035144 & 0.021090 & -1.67 & -0.035144 & 0.030570 & -1.15 & -0.056286 & 0.018471 & -3.05 \\
\hline NIKKEI Excess Return Lag & -0.055408 & 0.016851 & -3.29 & -0.055408 & 0.021196 & -2.61 & -0.036234 & 0.014021 & -2.58 \\
\hline DOW Excess Return Lag & 0.362194 & 0.022700 & 15.96 & 0.362194 & 0.029686 & 12.2 & 0.323260 & 0.020858 & 15.5 \\
\hline HangSeng Excess Return Lag & -0.000130 & 0.014822 & -0.01 & -0.000130 & 0.017495 & -0.01 & -0.008448 & 0.012659 & -0.67 \\
\hline Shanghai Excess Return Lag & -0.015425 & 0.014639 & -1.05 & -0.015425 & 0.014465 & -1.07 & -0.012697 & 0.010194 & -1.25 \\
\hline F-Values / Chi(2) & \multicolumn{3}{|c|}{47.02} & \multicolumn{3}{|c|}{28.58} & \multicolumn{3}{|c|}{258.58} \\
\hline
\end{tabular}


Table 5. ANOVA Results

\begin{tabular}{|c|c|c|c|c|c|}
\hline \multicolumn{6}{|c|}{ Panel A: Standard Error OLS/Newey-West } \\
\hline & Sum of Squares & df & Mean Square & $\mathrm{F}$ & Sig. \\
\hline Between Groups & 0.000015011 & 1 & 0.000015011 & 219.47 & 0 \\
\hline Within Groups & 0.000356616 & 5214 & $6.8396 \mathrm{E}-08$ & & \\
\hline Total & 0.000371626 & 5215 & & & \\
\hline \multicolumn{6}{|c|}{ Panel B: Predict OLS/GARCH } \\
\hline & Sum of Squares & df & Mean Square & $\mathrm{F}$ & Sig. \\
\hline Between Groups & 0.000094417 & 1 & 0.000094417 & 8.57 & 0.0034 \\
\hline Within Groups & 0.057473467 & 5214 & 0.000011023 & & \\
\hline Total & 0.057567884 & 5215 & & & \\
\hline
\end{tabular}

